\title{
Análisis de la epidemia de muertes infantiles en Talara durante el Fenómeno El Niño de 1997 - 1998: ¿estamos preparados para enfrentar otra?
}

\author{
Aníbal Del Águila ${ }^{1}$, Mónica Briceño ${ }^{2}$
}

Resumen

Palabras clave

\begin{abstract}
Los cambios climáticos producidos últimamente en el mundo debido al calentamiento global son motivo de preocupación creciente por su impacto en la salud y particularmente por su influencia en la presentación de las llamadas infecciones emergentes. Un aspecto poco estudiado de estas infecciones es el cambio en la virulencia y presentación clínica de infecciones producidas por agentes conocidos. La epidemia que ocasionó un elevado número de muertes infantiles en la provincia de Talara, durante el fenómeno El Niño de 1997 y 1998, fue producida por una enfermedad de presentación inusual, de rápida evolución y elevada mortalidad. La secuencia de síntomas, el examen físico y los resultados de laboratorio correspondieron a un patrón de infección viral. El compromiso neurológico nos planteó el diagnóstico de encefalitis, siendo el edema cerebral la causa de muerte de estos niños. El cuadro clínico pudo corresponder al de virus conocidos, como los arbovirus o al de los virus influenza, parainfluenza, adenovirus, echovirus, coxsackie, enterovirus, herpesvirus, entre otros, pero con mayor impacto a nivel del sistema nervioso central, o de un nuevo virus con características neurotrópicas. Analizamos la relación entre infecciones y elevación de temperatura. Destacamos la importancia de la historia clínica y el conocimiento de la fisiopatología de las infecciones virales para hacer su diagnóstico y la necesidad de estar preparados ante la presentación de una nueva epidemia en infraestructura, insumos y especialmente capacitación del personal de salud. En este sentido, se señala las limitaciones de los programas de salud vigentes. El mejoramiento de las condiciones de vida, saneamiento ambiental y cuidado del medio ambiente son la mejor manera de prevenir y controlar la presentación de infecciosas emergentes. Debemos aprender de las lecciones que nos dejó esta epidemia y del elevado número de muertes infantiles que ocasionó, para que no vuelvan a ocurrir. Fenómeno El Niño; alteraciones climáticas; brotes de enfermedades.
\end{abstract}

Analysis of children's deaths epidemic in Talara during the 1997-1998 El Niño Phenomenon: ¿are we prepared to face another one?

Abstract

World climate changes due to global warming causes increasing concern because of its impact on health and particularly its influence on the so called emerging infections. A poorly understood aspect of emerging infections is changes in virulence and clinical manifestations of known pathogens. The Talara province epidemic with a great number of children deaths during the 1997-1998 El

1 Médico Pediatra. Centro de Medicina y Rehabilitación Infantil ARIE. Lima, Perú.

2 Médico Pediatra. Policlínico Hermana María Donrose Sutmoller, EsSalud. Lima, Perú.
Niño phenomenon was produced by an unusual clinical disease with quick progression and high mortality. The clinical symptoms sequence, physical examination and laboratory data showed a viral infection pattern. The clinical neurological symptoms was due to encephalitis, and cerebral edema was the cause of death of these children. Many known viruses were probably responsible like arboviruses, influenza viruses, parainfluenza, adenoviruses, echoviruses, coxsackie, enteroviruses, and others, with mainly neurological complications. It could also be a new neuropathic virus, not recognized yet. We analyze the relationship between infections and high temperature. We point out the importance of the clinical history and knowledge of the pathophysiology of viral infections to diagnose these infections and the need to be prepared for a new epidemic with adequate infrastructure, equipments, medicines, and most important, training in early warning of the emergence of a new disease and rational therapeutics. The health programs had serious limitations to aid in this scenario. The best 
ways to prevent and control emerging infections is improving socioeconomic conditions of people, environmental sanitation and environmental condition. The cost of this epidemic was very high, with a high infantile mortality. We have to learn the lesson so it does not happen again.

Key words: El Niño phenomenon; climate changes; disease outbreaks.

\section{Introducción}

Los cambios climáticos producidos últimamente en todo el mundo debido al calentamiento global son motivo de preocupación creciente por su impacto en la salud y particularmente por su influencia en la presentación de las enfermedades infecciosas. El calentamiento global es producido principalmente por el incremento de la concentración de dióxido de carbono $\left(\mathrm{CO}_{2}\right)$ en la atmósfera. Desde 1957, en que se empezó a medir el nivel de este compuesto en la atmósfera, su incremento ha sido permanente y el aumento de la temperatura en el ámbito mundial ha sido directamente proporcional al aumento de $\mathrm{CO}_{2}\left({ }^{1}\right)$. La emisión de este gas resulta del consumo energético de combustibles fósiles, como carbono, petróleo y gas natural, en automóviles, barcos, aviones, pero sobretodo de las grandes plantas industriales de los países desarrollados, que emiten 2500 millones de toneladas al año $\left({ }^{2}\right)$.

El gran impacto del calentamiento global sobre la salud se puede dividir en dos grandes grupos; el impacto producido por los desastres naturales, como sismos, erupciones volcánicas, sequías, inundaciones, tornados, huracanes y tsunamis, cuya frecuencia e intensidad han aumentado últimamente, y el producido por el incremento en el número e incidencia de enfermedades infecciosas, conocidas como infecciones emergentes $\left.{ }^{3,4}\right)$.

Un aspecto de las infecciones emergentes es el resurgimiento de enfermedades infecciosas bajo control. Unas han vuelto a re- surgir con tasas sin precedentes y otras han aparecido en lugares donde no existían antes, este es el caso del dengue, la fiebre amarilla, la malaria, las diferentes fiebres hemorrágicas virales, las encefalitis virales, el cólera, la tuberculosis, la difteria, la leptospirosis, etc. Las enfermedades transmitidas por mosquitos, como malaria, fiebre amarilla, dengue y varios tipos de encefalitis, se encuentran entre las que mayor preocupación produce a medida que la temperatura del planeta aumenta. Uno de los mecanismos que explica este fenómeno es el aumento en el número e intensidad de las lluvias y cambios en su distribución geográfica. Estos cambios en la presentación de las lluvias producen aumento en la extensión y altitud sobre el nivel mar de los hábitats de diferentes vectores (mosquitos, roedores, garrapatas, etc.), con la formación de nuevos nichos ecológicos y aumento en la proliferación de estos vectores, portadores de diferentes agentes infecciosos $\left(^{5}\right)$. Aún un pequeño incremento en la temperatura tiene un efecto dramático en la distribución de mosquitos y garrapatas, portadores de diferentes virus, y determina cambios en los ciclos biológicos tanto de vectores como de diferentes agentes infecciosos, como se ha demostrado en el caso de la malaria, el dengue y la fiebre amarilla $\left(^{6}\right)$.

Además del resurgimiento de enfermedades conocidas, otro aspecto de las infecciones emergentes es la aparición de nuevas enfermedades infecciosas causadas por nuevos agentes patógenos. Entre 1951 y 1971, se descubrió no menos de 60 nuevos virus, no todos patógenos para el hombre $\left({ }^{7}\right)$, y en los últimos 25 años han aparecido cerca de 30 nuevas enfermedades, tales como el SARS (severe acute respiratory syndrome), la fiebre hemorrágica del Ébola, el sida, el síndrome pulmonar por Hantavirus, la gripe aviar, la hepatitis C, la enfermedad de Lyme, la fiebre hemorrágica venezolana, la fiebre hemorrágica brasileña, etc. $\left({ }^{8,9}\right)$. Algunas de estas nuevas infecciones no son 
causadas por verdaderos nuevos patógenos sino por diferentes agentes infecciosos (virus, bacterias, hongos, protozoarios y helmintos) que han encontrado una nueva forma de ingresar a un huésped susceptible (cruzar barrera de especie) y han sido reconocidos recientemente por técnicas sensibles desarrolladas últimamente $\left({ }^{3}\right)$. Ese es el caso del virus del sida, cuando fue identificado a principios de los 80'. La actual diversidad de enfermedades infecciosas que enfrenta la humanidad no tiene precedentes en la historia $\left({ }^{5}\right)$.

\section{Un episodio desapercibido de los primeros impactos del calentamiento global en el Perú}

Un aspecto poco estudiado y comprendido aún de las infecciones emergentes es el cambio de los patrones de virulencia de agentes infecciosos conocidos producido por el aumento de temperatura. La epidemia de muertes infantiles que ocurrieron en Talara, en el departamento de Piura, durante el fenómeno El Niño, de 1997 y 1998, es un ejemplo de lo que podría representar un cambio en la presentación clínica de una infección conocida debido al alza de temperatura. Es también una lección que nos deja muchas enseñanzas, para evitar o disminuir el costo en vidas por fenómenos climáticos como el fenómeno El Niño.

El fenómeno El Niño (EN), conocido también como ENSO (El Niño/Southern Oscillation), es un fenómeno climático que se presenta generalmente cada 3 a 4 años y es producto de la incursión de aguas tropicales en el Océano Pacífico Ecuatorial Central, que invaden el ámbito del sistema costero de la corriente del Humboldt, caracterizada por aguas frías y muy ricas en nutrientes y plancton. Cada vez que se presenta produce un impacto muy grande en casi todas las actividades humanas, con repercusiones en casi todo el mundo, pero particularmente en Perú, Ecuador, Chile,
Colombia y Bolivia. El calentamiento global afecta a El Niño y a los eventos climáticos en todo el mundo, aumentando su frecuencia e intensidad y por lo tanto su impacto en la salud, por el aumento de los desastres y las enfermedades que ellos producen. $\left({ }^{10,11}\right)$

Según el Instituto Nacional de Estadística e Informática (INEI), durante El Niño ocurrido entre los meses de diciembre de 1982 y marzo de 1983, que afectó al Perú principalmente a las poblaciones de la costa norte, se registró un incremento de hasta cuatro veces en la incidencia de enfermedades infecciosas y dos veces en la tasa de mortalidad infantil, especialmente por infecciones respiratorias e intestinales, respecto a los meses de verano de años anteriores.

El Niño de 1997 y 1998 fue calificado desde el mes de junio de 1997 como un evento de intensidad 'fuerte'. De acuerdo a los registros históricos, el fenómeno El Niño de estos años fue uno de los más fuertes del siglo pasado y rebasó en muchos aspectos a los de años anteriores $\left({ }^{10,12,13}\right)$. Las lluvias e inundaciones ocasionadas produjeron cuantiosas pérdidas en la agricultura, la pesca, la energía, las minas, los servicios básicos (salud, educación, etc.) y un severo daño a puentes y carreteras, aislando a los pueblos, principalmente en la costa norte del país. Se registró incremento en la incidencia de enfermedades infecciosas, tales como paludismo, cólera, bronconeumonía, dengue, infecciones respiratorias e intestinales, etc. en las poblaciones afectadas por este fenómeno, las cuales padecían malas condiciones de saneamiento ambiental, hacinamiento y pobreza $\left({ }^{13,14}\right)$.

Es en este contexto que, en el mes de diciembre de 1997, los médicos del Hospital Integrado IPSS-MINSA de la provincia de Talara alertaron sobre un incremento de la morbimortalidad en niños menores de 5 años, asociada a una entidad clínica de pre- 
sentación inusual, de rápida evolución y elevada mortalidad. Los diagnósticos iniciales planteados por los médicos de la localidad fueron diversos, tales como golpe de calor, hipernatremia, enfermedad diarreica aguda, bronconeumonía, meningoencefalitis, sepsis, convulsión febril, etc.

Esta situación concitó la atención y preocupación de organismos de salud nacionales e internacionales, quienes acudieron a esta provincia para el estudio y ejecución de medidas para detener esta epidemia de causa desconocida. Casos similares a los registrados en la provincia de Talara se registraron también en Trujillo, Huacho y Chimbote, ubicados también en la costa norte del Perú $\left({ }^{14}\right)$.

Es por esta razón que el Ministerio de Salud hizo un convenio con la Unidad de Posgrado de la Facultad de Medicina de la Universidad Nacional Mayor de San Marcos, para enviar residentes del tercer año de la especialidad de pediatría al hospital en mención, para contribuir con el estudio y tratamiento de estos pacientes. Los médicos que fueron enviados por la Facultad de Medicina de la UNMSM y el MINSA al hospital de Talara fueron la Dra. Rosa Alvarado, Dra. Mónica Briceño, Dr. Fernando Aburto y el Dr. Aníbal Del Águila.

Al llegar al hospital de Talara y evaluar los pacientes observamos en primer lugar la falta de camas para atender a todos los niños que requerían hospitalización. En segundo lugar, observamos diferentes esquemas de tratamiento para niños con los mismos síntomas, algunos con manitol, otros no; algunos con uno o varios antibióticos simultáneamente; otros con uno o dos anticonvulsivantes; unos con cloruro de sodio, otros con dextrosa; además de antipiréticos y broncodilatadores según el caso. Encontramos una niña que recibía cinco antibióticos al mismo tiempo. Una situación difícil de manejar fue el hecho de que a los niños no asegurados no se les dieran las mismas facilidades de atención que a los niños asegurados. Estos hechos demostraron deficiencias del sistema de salud por la falta de capacidad de respuesta en términos de infraestructura y personal ante esta situación extraordinaria, y la falta de uniformidad en el tratamiento y de criterios para una terapéutica racional.

Entre los meses de febrero y marzo de 1998, evaluamos y tratamos a un total de 26 niños, entre los 26 días y 5 años 3 meses de edad, a quienes vimos desde su ingreso al hospital hasta su alta o fallecimiento. El $57,7 \%(15 / 26)$ tenía entre 1 y 2 años de edad. Todos ellos presentaron una secuencia de síntomas que inició con fiebre en $34,6 \%(9 / 26)$, rinorrea o tos en $30,7 \%$ $(8 / 26)$, diarrea en $23,1 \%(6 / 26)$, vómitos en $7,7 \%(2 / 26)$ o somnolencia en $3,8 \%$ (1/ 26), a los que seguían, en número variable de horas o días, signos de compromiso sistémico y signos neurológicos, como irritabilidad, movimientos involuntarios, convulsiones o coma.

Los hallazgos al examen físico fueron similares en casi todos los pacientes: fiebre, congestión conjuntival, congestión faríngea, adenomegalias, estertores pulmonares (roncantes, subcrepitantes, crepitantes o sibilantes), taquicardia, hepatomegalia, irritabilidad o somnolencia, hipertonía y compromiso de conciencia, en grados variables, según la escala de disfunción cerebral de Lovejoy. El 100\% de los niños tuvo compromiso neurológico.

En algunos casos, estos signos fueron encontrados en el examen de ingreso y en otros se presentaron durante su hospitalización. Esto se debió a la alarma que esta epidemia produjo en la comunidad y a la capacitación en los centros de salud, lo cual logró que los niños fueran rápidamente traídos o derivados al hospital al inicio de los síntomas, y no con un curso avanzado de la enfermedad, como ocurría al empezar la 
epidemia. De esta manera, pudimos observar presencialmente el curso de la enfermedad. Aún así, tuvimos niños que llegaron al hospital con signos de choque y con compromiso severo de conciencia, que fallecieron a las pocas horas, a pesar de nuestros esfuerzos. En estos casos, las madres refirieron un curso bastante rápido, de horas, de la enfermedad.

Se realizó cultivos bacteriológicos de sangre en 18 de los niños y de líquido cefalorraquídeo (LCR) en 20 de ellos, todos ellos con resultados negativos. En los 20 niños con estudio del LCR, se encontró 5 o menos células en $70 \%$ de casos $(14 / 20)$ y con más de 5 células en $30 \%$ (6/20), hiperproteinorraquia en $45 \%$ de los casos $(9 / 20)$ e hiperglicorraquia mayor de $40 \mathrm{mg} /$ $100 \mathrm{~mL}$ en $90 \%$ de casos (18/20). En dos niños encontramos 101 y 752 células, respectivamente, a predominio de polimorfonucleares. Encontramos hiponatremia en $50 \%$ (9/18), hipernatremia en ningún caso, hiperglicemia en 58,3\% (7/12), hipokalemia en $78 \%(7 / 9)$, elevación de urea y creatinina en $75 \%(6 / 8)$, sedimento urinario patológico (leucocituria, cilindros leucocitarios o granulosos) en $46 \%$ de los niños $(6 / 13)$ y anemia en $67 \%(8 / 12)$. Un niño tuvo urocultivo positivo a Klebsiella sp. No fue posible obtener en todos los pacientes los exámenes auxiliares solicitados, por falta de recursos del hospital (medios de cultivo y reactivos).

Los residentes que fuimos enviados planteamos el diagnóstico clínico de proceso infeccioso viral $\left({ }^{15,16}\right)$, por la secuencia similar de eventos clínicos que presentaron estos niños, los hallazgos en su examen físico y de laboratorio, los cuales describen claramente un patrón de infección viral. Luego de ingresar al organismo, la mayoría de virus sigue un patrón de replicación y diseminación, estudiado y descrito por diferentes autores, que se manifiesta clínicamente por una secuencia de signos y síntomas que son expresión del compromiso de los diferentes órganos y sistemas $\left({ }^{17-22}\right)$. En los niños estudiados durante esta epidemia, observamos compromiso respiratorio, digestivo, ocular, renal, cardíaco (probable miocarditis) y neurológico. Durante su pasaje por el torrente circulatorio (viremia), los virus desencadenan respuesta inflamatoria en los lechos capilares de todo el organismo, sin que se produzca necesariamente replicación viral en las células de los diferentes órganos, excepto en las células por las cuales tenga tropismo en el llamado 'órgano blanco'. Tradicionalmente, las infecciones virales han sido definidas o categorizadas por el compromiso de un órgano blanco, p.e. parotiditis, hepatitis, neumonía, encefalitis, miocarditis, etc., pero todas ellas producen respuesta sistémica.

La presentación de signos y complicaciones neurológicas durante la evolución de la enfermedad nos condujo al diagnóstico de encefalitis, como parte del proceso infeccioso general o sistémico de etiología viral. Las manifestaciones clínicas neurológicas asociadas con edema cerebral en los pacientes evaluados variaron desde irritabilidad o somnolencia, convulsiones, náuseas y vómitos a letargia, estupor y coma profundo. El edema cerebral fue la causa de muerte de seis de los niños que tratamos y muy probablemente la causa de la todas las muertes en los meses anteriores, desde que se inició esta epidemia.

Por estas razones, nuestro tratamiento consistió en medidas de soporte, con manejo del volumen de agua y de electrólitos, de acuerdo a balance hídrico estricto y manitol (1-2 g/kg peso/dosis cada 4-8 h), además del tratamiento sintomático de la fiebre, convulsiones e hiperreactividad bronquial, según el caso. Solo recibió antibióticos un niño con sospecha de infección bacteriana, por tener elevado número de células a predominio de polimorfonucleares en LCR. Aún así, fue difícil determinar que la evolución favorable fuera debido a los antibióticos administrados, 
ya que se recuperó rápidamente. La tasa de letalidad fue $23 \%(6 / 26)$. La mortalidad reportada por la oficina de epidemiología para estas semanas epidemiológicas fue menor que la observada en los meses anteriores. De los 20 pacientes que fueron dados de alta, cuatro quedaron con secuelas neurológicas.

El hecho de que esta infección iniciara con diarrea o signos del aparato respiratorio explica por qué se plantearon erróneamente diagnósticos como EDA (enfermedad diarreica aguda) o IRA (infección respiratoria aguda), en un inicio, y que fueran tratados de acuerdo a los respectivos programas de atención que existen. Por esta misma razón creemos, que los reportes de incremento de mortalidad en niños por bronconeumonía y EDA durante la epidemia correspondieron verdaderamente a procesos infecciosos virales, por la similitud clínica con nuestros casos. Cuando se considera los signos o síntomas, diarrea o tos, en forma aislada, sin integrarlos o asociar uno con otro y no se observa toda la secuencia clínica, como revela la evolución de los pacientes que atendimos, no se hace un diagnóstico correcto, se prescribe tratamientos erróneos y se demora el inicio correcto del mismo. Muchas veces, sobretodo en lactantes y niños pequeños, son las manifestaciones generales o sistémicas las que sobresalen en el cuadro clínico y no la afección de un solo órgano o sistema y dependiendo de su severidad son hospitalizados por sospecha de sepsis bacteriana $\left({ }^{23,24}\right)$. $\mathrm{Si}$ desde el principio las manifestaciones neurológicas hubieran sido reconocidas tempranamente, quizás la tasa de letalidad hubiera sido menor, porque se habría tratado tempranamente el edema cerebral, que fue la causa de muerte de estos niños.

Como se sabe hasta la actualidad, los brotes epidémicos asociados a cambios estacionales son producidos en la mayoría de casos por infecciones virales, en todos los lugares donde ha sido posible determi- nar la etiología, señalándose a diferentes virus como agentes causales $\left({ }^{25-29}\right)$. Las mayores tasas de infección ocurren en poblaciones, especialmente en niños, que viven en condiciones de higiene pobre y hacinamiento, como ocurrió en la ciudad de Talara.

Aunque las pruebas de diagnóstico viral han tenido un importante desarrollo en los últimos años, el diagnóstico etiológico de una infección viral sigue siendo difícil en la práctica clínica, aún en los países con la más avanzada tecnología $\left({ }^{30}\right)$. Esto no siempre es posible, debido a las limitaciones en el aislamiento del virus en cultivos, ya que es necesario saber en qué período de la enfermedad y en qué espécimen biológico (sangre, heces, orina, LCR, hisopado faríngeo) es necesario tomar la muestra $\left({ }^{31,32}\right)$. Además, es posible que se aísle dos o más virus, sin poder determinar si alguno es responsable del cuadro infeccioso. Los análisis serológicos no siempre son contundentes, porque se puede encontrar anticuerpos contra uno o más virus sin poder precisar cuál es el agente responsable. La disponibilidad de estas pruebas requiere de una óptima realización a nivel técnico, una adecuada recolección y almacenamiento de la muestra y, principalmente, una interpretación acertada. Por esto su diagnóstico se basa fundamentalmente en la información clínica y el conocimiento de la fisiopatología de estas infecciones. El médico debe usar su juicio clínico para plantear la fuerte sospecha de infección viral.

El patrón de infección observado durante esta epidemia puede corresponder al de virus conocidos, como los arbovirus o los virus influenza, parainfluenza, adenovirus, echovirus, coxsackie, enterovirus, herpesvirus, entre otros, pero con mayor impacto a nivel del sistema nervioso central (SNC), durante esta epidemia. La mutación de un virus conocido da lugar a infecciones con síntomas que no producían antes, por ejemplo, síntomas neurológicos, y a nuevos síndromes clínicos, como el producido por 
ejemplo por el enterovirus $70\left({ }^{33}\right)$. Puede haberse tratado también de un nuevo virus, no reconocido aún, con características neurotrópicas. El compromiso del SNC es común en las infecciones virales emergentes. Este compromiso puede ser clínicamente evidente o no y a veces es diagnosticado solo por el estudio del LCR. Aún así, un pequeño porcentaje de pacientes con encefalitis viral tiene LCR sin pleocitosis, pero con cultivo positivo, por lo que su diagnóstico es fundamentalmente clínico $\left({ }^{34,35}\right)$. En nuestros pacientes, la mayoría de niños (70\%) tuvo LCR con 5 o menos células.

El Instituto Nacional de Salud aisló diferentes virus en pacientes con cuadros similares, en varias localidades de la costa peruana: parainfluenza I, parainfluenza II, parainfluenza III, adenovirus y virus respiratorio sincicial $\left({ }^{14}\right)$. A pesar de estos hallazgos y le evidencia clínica, el diagnóstico planteado por el Instituto fue el de golpe de calor. Los cuadros clínicos observados en estos niños no correspondieron en manera alguna al de este diagnóstico, porque el inicio de los síntomas no fue súbito y ninguno de ellos presentó hipernatremia, como ocurre característicamente en golpe de calor. A diferencia de éste, los síntomas de una infección viral empiezan generalmente con signos de ingreso por mucosa respiratoria o digestiva, a los que siguen una secuencia de signos y síntomas correspondientes con el patrón de replicación y diseminación ya descrito.

Los cambios en la presentación clínica de una infección o la presentación de nuevas infecciones en un contexto de cambios climáticos, deben dirigir nuestra atención a la influencia de la temperatura en la emergencia de enfermedades infecciosas. Se conoce que la elevación de temperatura produce cambios en la conducta de vectores y diferentes agentes infecciosos. La transmisión de enfermedades infecciosas es sensible a los cambios de temperatura por diferentes mecanismos: $\left({ }^{36}\right)$
1) El incremento de temperatura disminuye el periodo de incubación intrínseco del patógeno, por ejemplo, el parásito de malaria, el virus dengue o el de la fiebre amarilla, y así los vectores se tornan infecciosos más rápidamente $\left({ }^{6}\right)$.

2) El incremento de la temperatura también acelera el ciclo de vida de los vectores o permite que el vector colonice áreas previamente demasiado frías, llevando a una expansión de hábitat favorables de muchos vectores $\left(^{6}\right)$. Se conoce que aún un leve incremento de la temperatura tiene un efecto dramático en la distribución de mosquitos y garrapatas, portadores de diferentes virus $\left({ }^{7}\right)$.

3 ) La temperatura también afecta la conducta de la población humana, con relación a su exposición a la infección.

4) Los agentes virales y protozoarios pueden sobrevivir en agua, especialmente aguas temperadas, por largos períodos de tiempo y diseminarse en porcentajes incrementados en períodos de lluvias, incrementado su transmisibilidad entre la población $\left({ }^{37}\right)$.

Los virus coxsackie A y B, echovirus, poliovirus, enterovirus y adenovirus tienen un índice de replicación mayor a temperaturas superiores a $25{ }^{\circ} \mathrm{C}\left({ }^{38}\right)$. También, se ha observado modificaciones en la secuencia genética del virus influenza con temperaturas altas, que pueden ser mecanismos de adaptación y sobrevivencia y la causa de nuevas presentaciones clínicas. En modelos experimentales, el incremento de temperatura agrava la necrosis miocárdica inducida por virus $\left.{ }^{(39}\right)$.

La severidad de estas infecciones está relacionada al contexto en que se desarrollan, y es así que es mayor en condiciones de pobreza, desnutrición, exposición crónica a agentes infecciosos, hacinamiento y deficiente saneamiento ambiental $\left({ }^{37,40}\right)$. De igual manera, diversos aspectos de la vida humana (social, económico, cultural, político, tec- 
nológico, medio ambiente, conducta) pueden cambiar el patrón de una enfermedad e influir en su emergencia en una población $\left({ }^{41}\right)$. El mundo dinámico y globalizado en que vivimos, nuestra conducta y los cambios en la forma en que vivimos pueden alterar la oportunidad de supervivencia de los microorganismos, por lo que pueden mutar y adquirir nuevas características. No nos debe sorprender por tanto la emergencia o cambios en los patrones, virulencia y diseminación de las enfermedades; es más, deberíamos esperarlos.

\section{Reflexiones ante los futuros retos sanitarios con relación al Fenómeno El Niño y el Calentamiento Global}

Nuestra evaluación de los casos ocurridos en la epidemia en Talara durante el fenómeno El Niño, de 1997 y 1998, nos permite afirmar que su causa fueron procesos infecciosos virales, también llamados infecciones virales agudas generalizadas. La mayor repercusión a nivel neurológico fue una muestra del cambio en el cuadro clínico de las enfermedades infecciosas, debido al alza de temperatura.

¿Qué podemos hacer frente a estos fenómenos? ¿Podemos prevenirlos? Quizás no, porque nuevas enfermedades y nuevos virus van a aparecer de todas maneras. Pero, sí podemos, primero, tratar de comprender mejor la influencia de la conducta humana y los cambios climáticos en la ecología y la presentación de enfermedades, y segundo, estar preparados para cuando estas enfermedades se presenten y disminuir su impacto en la población.

La epidemia de Talara a fines de 1997 y principios de 1998, durante el fenómeno El Niño, nos mostró la limitación de los programas de salud que consideran al síntoma como enfermedad limitando la posibilidad de hacer un diagnóstico correcto, y que el planteamiento diagnóstico de una infección viral puede ser hecho mediante una adecuada elaboración de la historia clínica, con una anamnesis y examen físico minuciosos que permitan una interpretación clínica basada en el conocimiento de la fisiopatología de estas infecciones, más aún cuando no se cuenta con los recursos tecnológicos necesarios para un diagnóstico etiológico. En este sentido, los médicos, y particularmente los pediatras, debemos asumir el rol que nos corresponde en destacar la presentación frecuente de las infecciones virales en la población infantil. Nos mostró también la necesidad de una terapéutica racional basada igualmente en la interpretación clínica de los signos y síntomas. Durante esta epidemia, con la impresión diagnóstica de proceso infeccioso viral con mayor repercusión a nivel neurológico (encefalitis) nuestro tratamiento consistió principalmente en atender el edema cerebral, que fue la causa de la muerte de estos niños, con manejo estricto de la hidratación y la administración de manitol. Nos mostró también que no estamos preparados para enfrentar situaciones extraordinarias, pero previsibles, como las producidas por el fenómeno El Niño, en términos de infraestructura, insumos y capacitación del personal en la detección precoz de la emergencia de nuevas enfermedades y una terapéutica racional.

Durante nuestro trabajo en Talara, visitamos las postas y centros de salud aledaños y encontramos sumamente necesario e importante la capacitación del personal de salud, para la detección y tratamiento precoz de los niños con procesos infecciosos virales y compromiso neurológico. Como resultado, los niños recibieron un tratamiento más racional y fueron enviados tempranamente al hospital, al inicio de los síntomas.

Por todo lo expuesto, es necesario que el gobierno central, los gobiernos locales y la comunidad organizada dirijan sus esfuerzos hacia la mejora de las condiciones de las viviendas, del saneamiento ambiental y la 
erradicación de vectores, como las medidas más eficaces para la prevención y el control de las enfermedades infecciosas emergentes. Podemos en el ámbito local identificar cuáles son las mayores fuentes de gases de efecto invernadero y evitar la contaminación de la atmósfera, los ríos y el mar, y la deforestación indiscriminada de nuestros bosques. Estas medidas deben ser parte del esfuerzo por mejorar las condiciones de vida y elevar el nivel de salud de nuestra población, como objetivo principal, lo cual es necesariamente un trabajo multisectorial y no solamente de salud. El costo de estas lecciones ha sido muy alto, numerosas vidas humanas, como para no prestar atención a ellas y permitir que vuelva a ocurrir.

Finalmente, debemos entender que los cambios climáticos que producen la emergencia de nuevos patrones de enfermedad y nuevas enfermedades son en gran parte producidos por la gran emisión de gases con efecto invernadero de los 15 países más industrializados del mundo y por nuestra irresponsabilidad en el cuidado del planeta en que vivimos. A pesar de los esfuerzos por reducir la contaminación de la atmósfera con el Protocolo de Kyoto, firmado en 1998 por varios países, en el que se estipula compromisos obligatorios de limitación o reducción de la emisión de gases de efecto invernadero, los resultados no han sido los esperados, por conflictos de intereses, sobretodo económicos. Si no hacemos algo ahora, quizás luego sea muy tarde para lamentarnos y pretender corregir el daño hecho. El alto costo de esta epidemia es un llamado a corregir nuestra conducta y la convivencia con nosotros mismos y con la naturaleza, con la que compartimos la vida.

\section{REFERENCIAS BIBLIOGRÁFICAS}

1. Gribbin J. The greenhouse effect. New Scientist. 1988:1-4.

2. Natural Resources Defense Council (NRDC). Calentamiento global [monografía en Internet). New York: NRDC; [acceso 2 de mayo de 2007]. Disponible en: http://www.nrdc.org/ laondaverde/globalwarming/f101.asp
3. Colwell, R. Global climate and infectious disease: the cholera paradigm. Science. 1996;274:2025-31.

4. Amato V, Pasternak J. Emergent infections (editorial). Rev Inst Med Trop S Paulo. 1997;39(3):133-6.

5. Jackson E. Climate change and emerging infectious diseases. Health impacts. Med J Austral. 1995;163:570-4.

6. Huarcaya E, Rossi F, Llanos-Cuenta A. Influencia de factores climáticos sobre las enfermedades infecciosas. Revista Médica Herediana. 2004;15(4):218-24.

7. Ryan, F. Virus X. New York: Harper Collins Publishers; 1996 p. 53.

8. Stanchi, N. Editorial. Revista de enfermedades infecciosas emergentes [revista en Internet]. 2004 [acceso 9 de marzo de 2007]. Disponible en: http://www.geocities.com/ nestorstanchi/page4reie.html

9. Gestal Otero, J. Enfermedades Infecciosas emergentes: Alerta mundial, Respuesta Mundial. Rev Esp de Salud Pública. 1977;71(3):225-9.

10. Organización Mundial de la Salud. El Niño and Health. Protection of the Human Environment. Taske Force on Climate and Health [monografía en Internet] Geneve: OMS; 1999 [acceso 1 de mayo de 2007]. Disponible en: http:// www.who.int/globalchange/publications/en/elnino.pdf

11. Hong E. Globalisation and the impact on health. A Third World view [monografía en Internet]. Penang: Third World Network; 2000 [acceso 2 de mayo de 2007]. Disponible en: http://www.twnside.org.sg

12. Jenkins J. El Fenómeno de El Niño y los efectos en la Salud. El caso de Panamá. Panamá: OPS-Centro Regional de Información sobre Desastres- América Latina y el Caribe; 1998.

13. Organización Panamericana de la Salud. Crónicas de Desastres. Fenómeno El Niño 1997 - 1998. Washington, D.C.: OPS; 2000. p. 236.

14. Edición Especial Fenómeno «El Niño». Boletín del Instituto Nacional de Salud. 1998;4(1).

15. Alvarado R, Briceño, M. Encefalitis viral en niños menores de 5 años durante el fenómeno El Niño en Talara. Febrero 1998 [Tesis para optar título de especialista en Pediatría]. Lima: Facultad de Medicina, UNMSM; 2001.

16. Aburto F, Del Aguila A. El Fenómeno El Niño y los procesos infecciosos virales como causa de morbimortalidad en el brote epidémico en niños de la provincia de Talara. Talara - Marzo 1998 [Tesis para optar título de especialista en Pediatría]. Lima: Facultad de Medicina, UNMSM; 2002.

17. Roos KL. Encephalitis. Neurol Clin. 1999;17(4):813-33.

18. Epstein MA, Achong BG. Pathogenesis of infectious mononucleosis. Lancet. 1977;2(8051):1270-3.

19. Rickinson A, Yao QY, Wallace LE. The Epstein Barr virus as a model of virus host interactions. Br Med Bull. 1985;41(1):75-9.

20. Quiñonez Z. Separata del Curso de Pediatría. Lima: Facultad de Medicina, UNMSM; 1998

21. Collier L, Oxford J. Chap 4. How viruses cause disease. En: Human Virology. New York: Oxford University Press; 1993. p. 43-4. 
22. Zaoutis T, Klein JD. Enterovirus Infections. Pediatr Rev. 1998;19(6):183-91.

23. Dagan R, Powell K, Hall C, Menegus M. Identification of infants unlikely to have serious bacterial infection although hospitalized for suspected sepsis. J Pediatr. 1985;107(6):85560.

24. Dagan R, Hall C, Powell K, Menegus M. Epidemiology and laboratory diagnosis of infection with viral and bacterial pathogens in infants hospitalized for suspected sepsis. J Pediatr. 1989;115(3):351-6.

25. Fox J. Epidemiology of infectious diseases. En: Feigin R, Cherry J. Eds. Textbook of Pediatric Infectious Diseases. $3^{\text {rd }}$ Ed. Philadelphia: Saunders; 1992. p. 79-95.

26. Jenista J, Powell K, Menegus M. Epidemiology of neonatal enterovirus infection. J Pediatr. 1984;104(5):685-90.

27. Spencer M, Cherry J. Adenoviral infections. En: Feigin R, Cherry J. Textbook of Pediatric Infectious Diseases, $3^{\text {rd }}$ Ed. Philadelphia: Saunders; 1992. p. 1279-91.

28. Rotbart HA. Clinical significance of enteroviruses in serious summer febrile illnesses of children. Pediatr Infect Dis J. 1999;18(10):869-74.

29. Ebi KL, Exuzides KA, Lau E, Kelsh M, Barnston A. Association of normal weather periods and El Niño events with hospitalization for viral pneumonia in females: California, 1983-1998. Am J Public Health. 2001;91(8):1200-8.

30. Crespo MP. El diagnóstico viral por el laboratorio. Colombia Médica. 2000;31:135-50.

31. Dagan R, Jenista J, Prather S, Powell K, Menegus M. Viremia in hospitalized children with enterovirus infections. J Pediatr. 1985;106(3):397-401.

32. Morag A, Ogra P. Enteroviruses. En: Behrman R, Kliegman $\mathrm{R}$, Arvin A. eds. Textbook of Pediatrics. Philadelphia, $\mathrm{Pa}$ : WB Saunders Co; 2000. p. 964.

33. Johnson R. Emerging viral infections. Arch Neurol. 1996;53:18-22.

34. Dagan R, Jenista J, Menegus M. Association of clinical presentation, laboratory findings, and virus serotypes with the presence of meningitis in hospitalizad infants with enterovirus infection. J Pediatr. 1988;113(6):975-8.

35. Whitley R. Viral encephalitis. N Engl J Med. 1990;323(4):242-9.
36. Kovats RS, Bouma MJ, Haines A. El Niño and health. Protection of the human environment. Task Force on Climate and Health. Geneva: Bull World Health Organization; 1999. p. 14-8.

37. Canziani O, Diaz S. Latinoamerica: Human Health [monografía en Internet]. En: Watson R, Zinyowera M, Moss R. Intergovernmental panel on climate change (IPCC): an assesment of vulnerability. Geneva: IPCC; [acceso $11 \mathrm{de}$ Mayo de 2007]. Disponible en: http://www.grida.no/climate/ ipcc/regional/index.htm

38. Woody MA, Cliver DO. Effects of temperature and host cell growth phase on replication of F-specific RNA coliphage Q beta. Appl Environ Microbiol. 1995;61(4):1520-6.

39. Kanda T, Nakano M, Yokoyama T, Hoshino Y, Okajima F, Tanaka T, et al. Heat stress aggravates viral myocarditis in mice. Life Science. 1999;64(2):93-101.

40. Adger N, Aggarwall P, Agrawala S, Alcamo J, Allali A, Anisimov O. Climate change 2007: Impacts, adaptation and vulnerability. Working Group II Contribution to the Intergovernmental Panel of Climate Change (IPCC) [monografía en Internet]. Fourth Assessment Report. Brussels: World Meteorological Organization and United Nations Environment Programme; 2007 [acceso 11 de Mayo de 2007]. Disponible en: http://www.ipcc.ch/ SPM13apr07.pdf

41. Ebi K, Mills D, Smith J, Grambsch A. Climate change and human health impacts in the United States: An update on the results of the U.S. National Assessment. Environmental Health Perspectives. 2006; $114(9): 1318-1324$.

Manuscrito recibido el 03 de julio de 2007 y aceptado para publicación el 02 de agosto de 2007.

\section{Correspondencia:}

Aníbal Del Águila Escobedo

Av. José Pardo 930 Dpto. 202

Lima 18, Perú.

Correo-e: adelaguila80@yahoo.com 